\title{
Technology Acceptance Model pada Sistem Informasi Akademik berbasis Web
}

\author{
Yovita Kinanti Kumarahadi ${ }^{1)}$, Kumaratih Sandradewi ${ }^{2)}$ \\ 1) Informatika, STMIK Sinar Nusantara Surakarta \\ 2) Sistem Informasi Akuntansi, STMIK Sinar Nusantara Surakarta \\ 1) yovitakinan@sinus.ac.id, ${ }^{2)}$ kumaratih@sinus.ac.id
}

\begin{abstract}
Academic information system is an important system in students' learning's activities because it is used as connector between students and lecturers. In addition, academic information system also acts as a liaison between lecturers and other relevant external parties. Academic information system provides several services, both for students and lecturers. These facilities include the provision of information on study plans, grades, schedules, and courses. However, only a few facilities are frequently used so that the use of the academic information system is not optimal.

The problem in this study is the need for an evaluation to determine the acceptance of the academic information system by users, so that the system can be improved and developed. This study aimed to determine the acceptance of web-based academic information system by users at STMIK Sinar Nusantara Surakarta with the Technology Acceptance Model or TAM. The results of this study are perceived ease of use, perceived usefulness, attitude toward usage, and behavioral intention to use have a significant positive effect on actual usage behavior.
\end{abstract}

Keywords : Technology Acceptance Model, academic information system, web-based system

\section{PENDAHULUAN}

Sistem informasi akademik atau siakad adalah sistem yang cukup penting dalam kegiatan pembelajaran mahasiswa karena berfungsi sebagai media penghubung antara mahasiswa dengan dosen. Selain itu, sistem informasi akademik juga menjadi penghubung antar dosen, serta dengan pihak luar yang bersangkutan. Sistem informasi akademik menyediakan beberapa layanan, baik bagi mahasiswa maupun dosen. Fasilitas tersebut antara lain penyediaan informasi rencana studi, nilai, jadwal, serta mata kuliah. Namun, hanya beberapa fasilitas yang sering digunakan sehingga pemakaian sistem informasi akademik menjadi tidak maksimal.

Terdapat beberapa model untuk mengetahui tingkat penerimaan teknologi dari segi pengguna. Model yang pertama adalah Theory of Reason Action yaitu model yang dapat memprediksi serta menjelaskan perilaku variasi dari domain. Kekurangan dari model ini adalah tidak adanya konstruk kontrol. Model yang kedua adalah Theory of Planned Behaviour yang memiliki konstruk kontrol di dalamnya (Venkatesh \& Davis, 1996). Model yang ketiga adalah Technology Acceptance Model, yaitu model untuk mengetahui penerimaan pengguna terhadap sistem informasi.

Technology Acceptance Model mampu menjelaskan sebesar 40\% niat perilaku untuk menggunakan teknologi. Penelitian yang menggunakan TAM antara lain (Alharbi \& Drew, 2014; Dharmawan et al., 2018; Fathema et al., 2015; Handayani, 2013; Librado, 2017; Mulyani \& Kurniadi, 2015). Hasil yang didapatkan masih cukup beragam, maka dari itu penelitian lebih lanjut dengan menggunakan Technology Acceptance Model sangat dianjurkan.

Penelitian ini memiliki tujuan untuk mengetahui penerimaan teknologi, yaitu siakad, oleh pengguna. Dengan mengetahui hasil penerimaan ini, manajemen akan mampu untuk mengambil keputusan, antara lain pengembangan sistem seperti apa yang perlu dilakukan supaya sistem dapat lebih diterima oleh pengguna. 


\section{TINJAUAN PUSTAKA}

Analisis tentang penerapan sistem sudah pernah dilakukan oleh beberapa peneliti. Suryawan dan Prihandoko (2018) mengevaluasi penerapan SIAKAD pada Politeknik Negeri Madiun. Hasil penelitian ini yaitu SIAKAD PNM diterima dalam kemudahan \& kemanfaatan secara individual maupun simultan. Kemudian format, accuracy, content, ease, dan timeline berpengaruh secara simultan. Sedangkan, content dan ease berpengaruh secara individual.

Librado (2017) menganalisa penerimaan SIAKAD oleh mahasiswa untuk mengetahui bagaimana perilaku pengguna SIAKAD sebagai pengguna akhir. Hasil penelitian ini yaitu variabel berpengaruh signifikan positif. Faktor penerimaan teknologi yang menyebabkan perilaku menggunakan SIAKAD adalah kemudahan dan kegunaan.

Dharmawan, Fitriasih, dan Irawati (2018) menerapkan TAM untuk mengetahui pengukuran penggunaan aplikasi oleh pengguna yang bersangkutan. Hasil penelitian ini yaitu interface design dan user behavior berpengaruh terhadap penggunaan nyata.

Alharbi dan Drew (2014) melakukan penelitian yang bertujuan untuk memberikan prediksi niat penggunaan Learning Management Systems (LMS). Hasil penelitian ini yaitu seluruh variabel berpengaruh secara langsung dan tidak langsung.

Fathema, Shannon, dan Ross (2015) meneliti bagaimana keyakinan dan sikap mempengaruhi minat dan penggunaan nyata LMS di institusi, dalam kondisi yang tidak mewajibkan penggunaan sistem tersebut. Hasil penelitian ini yaitu semua variabel eksternal berpengaruh signifikan pada sikap perilaku penggunaan.

Dari berbagai penelitian dengan menggunakan variabel yang berbeda-beda, penelitian ini secara khusus melihat penerimaan teknologi dari variabel Perceived Ease of Use, Perceived Usefulness, Attitude Toward Using, Behavioral Intention to Use, dan Actual Usage Behavior. Pemilihan variabel ini berdasarkan model yang digunakan, yaitu Technology Acceptance Model.

\section{METODE PENELITIAN}

Metode penelitian merupakan prosedur dan teknik penelitian. Antara satu penelitian dan penelitian lain, prosedur dan tekniknya akan berbeda. Apabila tidak berbeda berarti penelitian itu hanya mengulang penelitian yang telah ada sebelumnya.

\subsection{Jenis, Sifat, Pendekatan Penelitian}

Penelitian memerlukan data dalam mengungkap fakta yang diharapkan dapat sesuai dengan tujuan penelitian. Data yang digunakan dalam penelitian ini adalah data primer. Data primer merupakan data yang dikumpulkan langsung oleh peneliti dari sumber utamanya. Data primer yang dikumpulkan berupa angket yang disebarkan kepada mahasiswa STMIK Sinar Nusantara Surakarta.

Penelitian ini bertujuan untuk menguji hipotesis. Sekaran \& Bougie (2013) menyatakan bahwa pengujian hipotesis menjelaskan sifat dari hubungan tertentu atau membangun perbedaan dalam kelompok, maupun independensi dari dua atau lebih faktor pada sebuah situasi. Pengujian hipotesis digunakan untuk memberikan penjelasan mengenai perbedaan dalam variabel dependen. Penelitian ini menggunakan tipe investigasi penelitian kausal. Penelitian kausal adalah penelitian yang bertujuan untuk menggambarkan sebab dari satu masalah atau lebih.

Metode pengumpulan data yang dilakukan pada penelitian ini adalah observasi, angket, dan studi literatur. Observasi dilakukan secara langsung melalui Sistem Informasi Akademik Online STMIK Sinar Nusantara Surakarta. Angket yang disebarkan pada responden merupakan angket tertutup. 


\subsection{Populasi, Sampel, Teknik Pengambilan Sampel}

Populasi penelitian ini adalah pengguna yang telah menggunakan sistem informasi akademik online selama lebih dari satu tahun, yaitu terdiri dari mahasiswa aktif semester genap, dosen, dan karyawan BAAK di STMIK Sinar Nusantara Surakarta. Sampel penelitian didapatkan dengan menggunakan teknik Proportionate Stratified Random Sampling. Teknik ini digunakan karena populasi penelitian tidak homogen dan berstrata secara proporsional. Perhitungan jumlah sampel menggunakan rumus Slovin pada persamaan 1.

$$
n=\frac{N}{1+N(e)^{2}} \cdots \cdots \cdots
$$

dimana $\mathrm{n}=$ ukuran sampel, $\mathrm{N}=$ jumlah populasi, dan $\mathrm{e}=$ alpha. Perhitungan jumlah sampel berstrata dilakukan dengan menggunakan rumus alokasi proportional pada persamaan 2.

$$
n i=\frac{N i}{N} \times n
$$

dimana $\mathrm{ni}=$ jumlah sampel menurut stratum, $\mathrm{n}=$ jumlah sampel seluruhya, $\mathrm{Ni}=$ jumlah populasi menurut stratum, dan $\mathrm{N}=$ jumlah populasi seluruhnya.

\subsection{Variabel Penelitian}

Variabel yang digunakan pada penelitian ini yaitu persepsi kemudahan penggunaan (perceived ease of use) sebagai variabel bebas pertama (X1), persepsi kegunaan (perceived usefulness) sebagai variabel bebas kedua (X2), sikap perilaku penggunaan (attitude toward using) sebagai variabel bebas ketiga (X3), minat perilaku penggunaan (behavioral intention to use) sebagai variabel bebas keempat (X4), dan penggunaan nyata (actual usage behavior) sebagai variabel dependen (Y).

\subsection{Model Penelitian}

Model yang digunakan pada penelitian adalah Technology Acceptance Model (Davis, 1989).

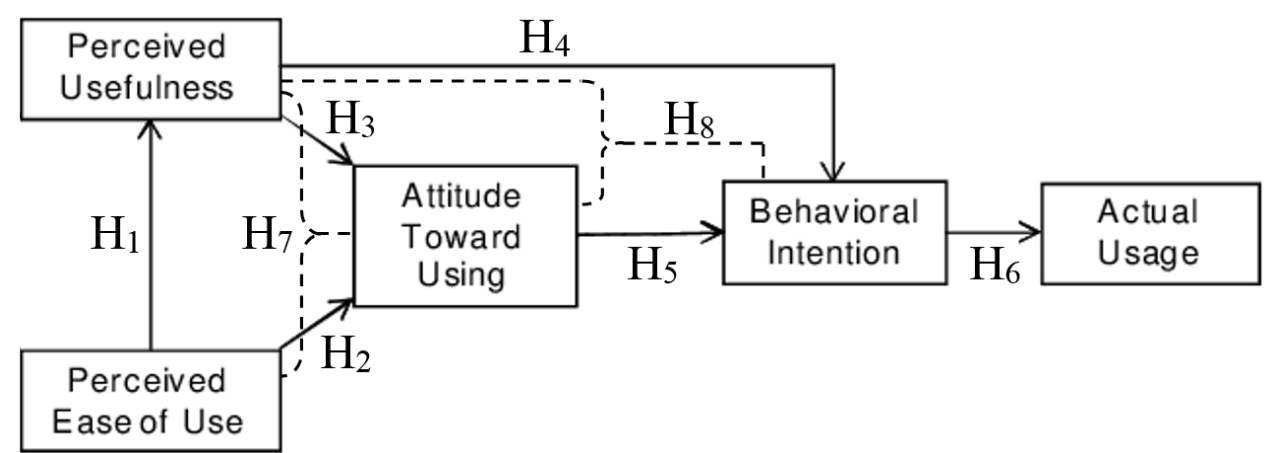

Gambar 1. Model Penelitian

Gambar 1 menunjukkan bahwa terdapat lima konstruk dalam Technology Acceptance Model, yaitu Perceived Ease of Use, Perceived Usefulness, Attitude Toward Using, Behavioral Intention to Use, dan Actual Usage Behavior.

\subsection{Metode Analisis Data}

Dalam melakukan analisis data, terdapat beberapa tahapan yang dilakukan: pengujian alat pengambil data, analisis data, pengujian kualitas data, dan pengujian hipotesis. 
Pengujian alat pengambil data terdiri dari uji validitas dan uji reliabilitas. Uji ini dilakukan untuk memastikan bahwa kuesioner yang digunakan untuk mengambil data dapat menggambarkan populasi berdasarkan sampel yang diambil.

Analisis data yang digunakan adalah analisis diagram path, goodness of fit untuk pengujian validitas, dan analisa pengaruh dan jalur. Analisa ini dilakukan untuk menggambarkan jalur koefisien konstruksi dari tiap variabel yang telah digunakan, mengevaluasi model dan pengukuran dari setiap variabel penelitian, dan mengetahui pengaruh dari setiap jalur antar variabel serta besar pengaruh yang dimiliki.

Pengujian kualitas data atau uji asumsi klasik terdiri dari normalitas, multikolinearitas, dan heterokedastisitas. Pengujian hipotesis dilakukan dalam tiga tahap, yaitu regresi linier berganda, perhitungan nilai koefisien determinasi, dan uji hipotesis f-test. Uji hipotesis dilakukan untuk mengetahui hubungan antar variabel, mengukur seberapa besar pengaruh variabel, dan menguji apakah variabel bebas berpengaruh secara signifikan terhadap variabel terikat secara simultan.

\subsection{Prosedur Penelitian}

Berdasarkan uraian sebelumnya, dapat ditentukan prosedur penelitian seperti pada Gambar 2.

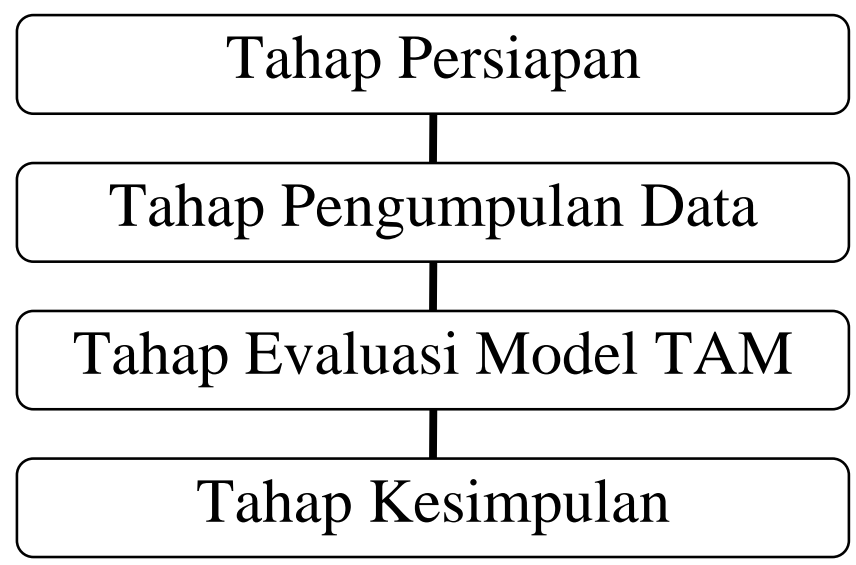

Gambar 2. Alur Penelitian

Alur penelitian terdiri dari tahap persiapan, tahap pengumpulan data, tahap evaluasi model TAM, dan tahap kesimpulan. Pada tahap persiapan, proses yang dilakukan adalah perumusan masalah, penentuan judul, penetapan tujuan, dan studi literatur. Pada tahap pengumpulan data, proses yang dilakukan adalah penentuan metode dan variabel, perumusan hipotesis, penyusunan kuisioner, dan penyebaran kuisioner. Pada tahap evaluasi model TAM, proses yang dilakukan adalah pengujian alat pengambil data, analisis data, pengujian kualitas data, dan pengujian hipotesis. Pada tahap kesimpulan, proses yang dilakukan adalah penarikan kesimpulan sesuai hasil analisa data.

\section{HASIL DAN PEMBAHASAN}

\subsection{Hasil Pemilihan Sampel}

Sampel penelitian didapatkan dengan menggunakan persamaan 1 dengan alpha 5\%, kemudian ditentukan besaran sampel per stratum dengan menggunakan persamaan 2 . Stratum yang digunakan dilihat dari kategori responden di STMIK Sinar Nusantara Surakarta, yaitu mahasiswa, dosen, dan karyawan. Sampel merupakan jumlah minimal responden dalam penelitian yang ditentukan supaya masing-masing jenis responden dapat terwakili. Jumlah sampel dapat dilihat dari Tabel 1. 
Tabel 1 Populasi dan Sampel

\begin{tabular}{|c|r|r|}
\hline Kategori & Populasi & Sampel \\
\hline Mahasiswa & 746 & 247 \\
\hline Dosen & 57 & 19 \\
\hline Karyawan & 4 & 1 \\
\hline Jumlah & 807 & 267 \\
\hline
\end{tabular}

Kuisioner yang diterima kembali akan diperiksa terlebih dahulu untuk memilih kuisioner yang dapat diolah dan tidak dapat diolah. Penulis menyebarkan kuisioner sejumlah 380 kuisioner bagi mahasiswa, 20 kuisioner bagi dosen, dan 4 kuisioner bagi karyawan BAAK. Dari kuesioner yang disebarkan, hanya 312 kuisioner mahasiswa yang kembali, sehingga total kuesioner yang digunakan untuk pengolahan data adalah 334 kuesioner.

\subsection{Pengujian Alat Pengambil Data}

Pada penelitian ini, uji alat pengambil data yang dilakukan adalah uji validitas dan uji reliabilitas. Hasil dari uji validitas adalah seluruh item pertanyaan valid dan dapat diolah. Kemudian, hasil dari uji reliabilitas adalah didapat nilai reliabilitas instrumen sebesar 0,616 . Hal ini menunjukkan bahwa kuisioner penelitian sudah reliabel karena lebih besar dari 0,6 .

\subsection{Pengujian Analisis Data}

Pada penelitian ini, analisis data yang digunakan adalah diagram path, goodness of fit, dan analisa pengaruh dan jalur. Diagram path terdapat pada Gambar 3.

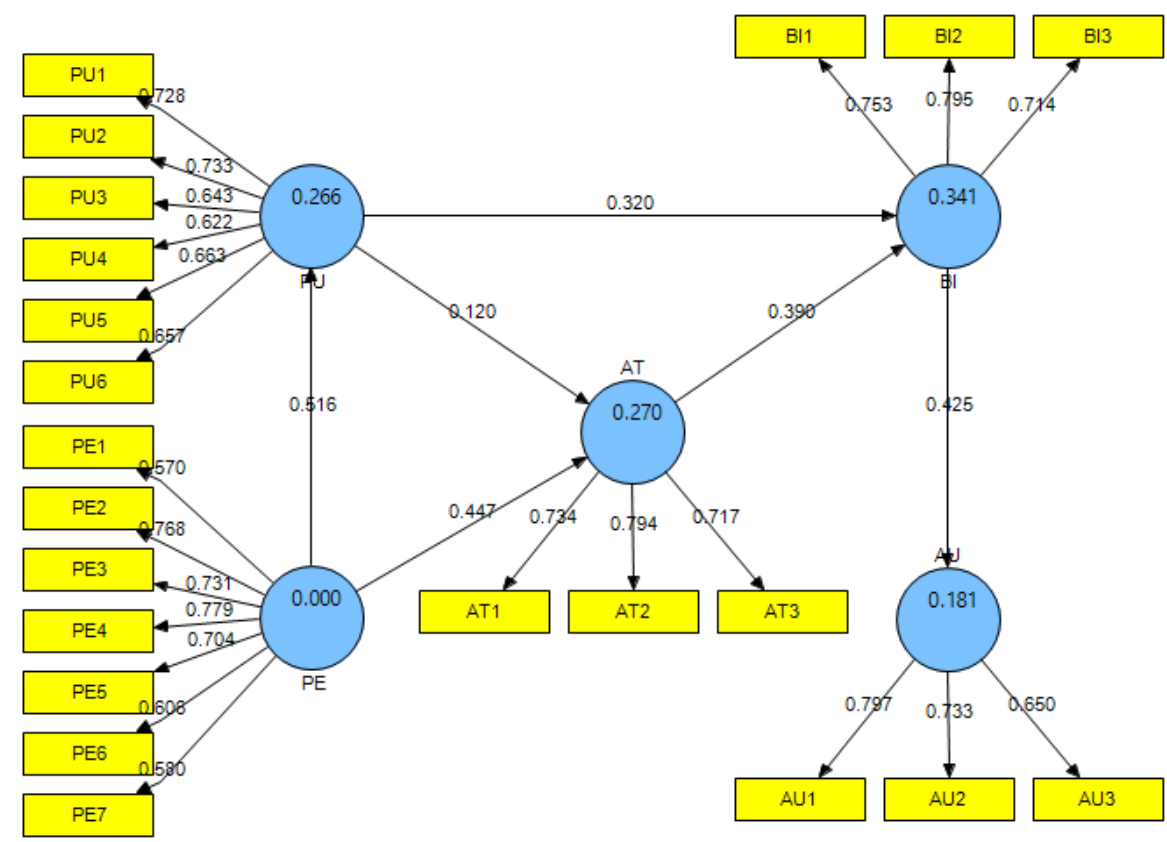

Gambar 3. PLS Algorithm Output

Berdasarkan analisis goodness of fit, indikator pada model valid secara convergent (dari nilai loading factor yang lebih besar dari 0,5), variabel valid secara discriminant (dari nilai AVE yang lebih besar dari 0,5 dan cross loading yang memiliki nilai paling besar dipersilangan variabelnya), seluruh indikator signifikan (dari t-value pada model bootstrap 
yang lebih besar dari nilai tabel z), dan didapatkan nilai $\mathrm{Q}^{2}$ sebesar $71 \%$ (dari inner models).

Dari analisa pengaruh dan jalur, dapat disimpulkan bahwa PE, PU, dan AT tidak berpengaruh langsung terhadap AU, sedangkan BI berpengaruh langsung terhadap AU. Besar pengaruh variabel dapat diketahui dari analisis Path Coefficients, yaitu $\mathrm{PE} \Rightarrow \mathrm{AU}$ sebesar 0,154 dan 2\%; PU $\Rightarrow$ AU sebesar 0,156 dan 3\%; AT $\Rightarrow$ AU sebesar 0,166 dan $4 \%$; dan $\mathrm{BI}=>$ AU sebesar 0,425 dan $18 \%$.

\subsection{Pengujian Kualitas Data}

Terdapat empat tahapan dalam uji asumsi klasik ini, yaitu uji normalitas, uji autokorelasi, uji multikolinearitas, dan uji heterokedastisitas. Berdasarkan uji asumsi klasik, dapat diambil kesimpulan bahwa data telah lolos uji normalitas, bebas dari autokorelasi, tidak terjadi multikolinearitas, dan bebas heterokedastisitas. Uji asumsi klasik dilakukan dengan menggunakan aplikasi statistik SPSS.

\subsection{Pengujian Hipotesis}

Pengujian hipotesis dilakukan dalam tiga tahap, yaitu regresi linier berganda, perhitungan nilai koefisien determinasi, dan uji hipotesis f-test. Berdasarkan pengolahan data yang telah dilakukan, terdapat dua model regresi liner berganda, yaitu Model $1=\mathrm{PU}$ $+\mathrm{PE}=\mathrm{AT}$ dan Model $2=\mathrm{PU}+\mathrm{AT}=\mathrm{BI}$.

Berdasarkan perhitungan nilai koefisien determinasi, didapat nilai $\mathrm{R}^{2}$ Model 1 sebesar $27 \%$ dan nilai $\mathrm{R}^{2}$ Model 2 sebesar 33,5\%. Model 1 dipengaruhi oleh variabel PE dan PU secara simultan sebesar $27 \%$ dan dipengaruhi variabel lain di luar model sebesar $73 \%$. Model 2 di pengaruhi oleh variabel PU dan AT secara simultan sebesar 33,5\% dan dipengaruhi variabel lain di luar model sebesar 66,5\%.

Uji hipotesis f-test menunjukkan bahwa PE dan PU berpengaruh secara simultan signifikan terhadap AT, lalu PU dan AT juga berpengaruh secara simultan signifikan terhadap BI.

Hasil dari analisis yang telah dilakukan menunjukkan bahwa seluruh hipotesis diterima, dengan penjelasan sebagai berikut: 1) persepsi kemudahan penggunaan berpengaruh positif signifikan terhadap persepsi kegunaan; 2) persepsi kemudahan penggunaan berpengaruh positif signifikan terhadap sikap perilaku penggunaan; 3) persepsi kegunaan berpengaruh positif signifikan terhadap sikap perilaku penggunaan; 4) persepsi kegunaan berpengaruh positif signifikan terhadap minat perilaku penggunaan; 5) sikap perilaku penggunaan berpengaruh positif signifikan terhadap minat perilaku penggunaan; 6) minat perilaku penggunaan berpengaruh positif signifikan terhadap penggunaan nyata; 7) persepsi kemudahan penggunaan dan persepsi kegunaan berpengaruh terhadap sikap perilaku penggunaan; dan 8) persepsi kegunaan dan sikap perilaku penggunaan berpengaruh terhadap minat perilaku penggunaan.

\section{KESIMPULAN DAN SARAN}

\subsection{Kesimpulan}

Tujuan dari penelitian ini adalah untuk menganalisis penerimaan informasi akademik Sistem informasi akademik berbasis web di STMIK Sinar Nusantara Surakarta. Model yang digunakan adalah TAM yang berisi persepsi kemudahan, persepsi kegunaan, dan penerimaan teknologi. Penerimaan terdiri dari sikap perilaku penggunaan, minat perilaku penggunaan, dan penggunaan nyata. Setelah dilakukan pengujian dan analisis penelitian, dapat disimpulkan bahwa seluruh variabel berpengaruh signifikan positif dan seluruh hipotesis diterima. 
Persepsi kemudahan penggunaan berpengaruh terhadap persepsi kegunaan dengan nilai koefisien beta sebesar 0,516 dan t-value 8,665. Persepsi kemudahan penggunaan berpengaruh terhadap sikap perilaku penggunaan dengan nilai koefisien beta sebesar 0,509 dan t-value 13,525.

Persepsi kegunaan berpengaruh terhadap sikap perilaku penggunaan dengan nilai koefisien beta sebesar 0,120 dan t-value 2,148. Persepsi kegunaan berpengaruh terhadap minat perilaku penggunaan dengan nilai koefisien beta sebesar 0,366 dan t-value 5,787.

Sikap perilaku penggunaan berpengaruh terhadap minat perilaku penggunaan dengan nilai koefisien beta sebesar 0,390 dan t-value 7,343. Minat perilaku penggunaan berpengaruh terhadap penggunaan nyata dengan nilai koefisien beta sebesar 0,425 dan tvalue 9,548 .

Persepsi kemudahan penggunaan dan persepsi kegunaan berpengaruh terhadap sikap perilaku penggunaan dengan $\mathrm{f}$ hitung sebesar 61,588 dan koefisien determinasi sebesar 27\%. Persepsi kegunaan dan sikap perilaku penggunaan berpengaruh terhadap minat perilaku penggunaan dengan $\mathrm{f}$ hitung sebesar 83,773 dan koefisien determinasi sebesar $33,5 \%$.

\subsection{Saran}

Saran untuk penelitian selanjutnya adalah penambahan variabel lain untuk untuk melihat pengaruhnya terhadap Technology Acceptance Model. Kemudian, saran untuk Sistem informasi akademik berbasis web adalah pemberian petunjuk penggunaan supaya fasilitas yang disediakan bisa digunakan secara maksimal. Selain itu, terdapat saran dari pengguna untuk lebih memperhatikan jaringan di laboratorium komputer sebab koneksinya masih sering terputus. Saran lain ialah untuk menambahkan kotak saran yang akan berguna untuk menampung pendapat pengguna, baik mahasiswa, dosen, maupun karyawan. Dengan adanya kotak saran tersebut, diharapkan kritik dan saran pengguna bisa langsung sampai pada pengelola sistem informasi akademik berbasis web STMIK Sinar Nusantara Surakarta.

\section{DAFTAR PUSTAKA}

Alharbi, S., \& Drew, S. (2014). Using The Technology Acceptance Model In Understanding Academics' Behavioural Intention To Use Learning Management Systems. International Journal of Advanced Computer Science and Applications, 5(1), $143-155$.

http://citeseerx.ist.psu.edu/viewdoc/download?doi=10.1.1.428.9465\&rep=rep1\&type= pdf

Davis, F. D. (1989). Perceived Usefulness, Perceived Ease Of Use, and User Acceptance Of Information Technology. MIS Quarterly, 319-340. https://www.jstor.org/stable/249008

Dharmawan, A. R., Fitriasih, S. H., \& Irawati, T. (2018). Analisa Penerapan Aplikasi Penjualan Dan Service Komputer Pada Cv Jaya Citra Madani Dengan Metode Technology Acceptable Model (TAM). Jurnal Ilmiah SINUS, 16(1), 65-74. https://p3m.sinus.ac.id/jurnal/index.php/e-jurnal_SINUS/article/view/332

Fathema, N., Shannon, D., \& Ross, M. (2015). Expanding The Technology Acceptance Model (TAM) to Examine Faculty Use of Learning Management Systems (LMSs) In Higher Education Institutions. MERLOT Journal of Online Learning and Teaching, 11(2), 211-232. http://jolt.merlot.org/Vol11no2/Fathema_0615.pdf

Handayani, T. (2013). Analisis Penerimaan Sistem Informasi Akademik Berbasis Web Mengunakan Technology Acceptance Model (TAM) dan Usability (Studi Kasus pada STTNAS Yogyakarta). Prosiding Seminar Nasional Rekayasa Teknologi Industri Dan 
Informasi, 101-107. https://journal.sttnas.ac.id/ReTII/article/view/120

Librado, D. (2017). Analisis Penerimaan Mahasiswa Terhadap Sistem Informasi Akademik (SIAKAD) Dengan Metode Technology Acceptance Model (TAM). Jurnal SAINTEKOM, $7(2)$

$112-125$.

http://stmikplk.ac.id/jurnal/index.php/saintekom/article/view/29

Mulyani, A., \& Kurniadi, D. (2015). Analisis Penerimaan Teknologi Student Information Terminal (S-IT) Dengan Menggunakan Technology Acceptance Model (TAM). Jurnal Wawasan Ilmiah, 7(12).

Sekaran, U., \& Bougie, R. (2013). Research Methods For Business: A Skill-Building Approach. Wiley.

Suryawan, M. B., \& Prihandoko, P. (2018). Evaluasi Penerapan SIAKAD Politeknik Negeri Madiun Menggunakan Pendekatan TAM dan EUCS. Creative Information Technology Journal, 4(3), 233-244. http://citec.amikom.ac.id/main/index.php/citec/article/view/113

Venkatesh, V., \& Davis, F. D. (1996). A Model Of The Antecedents Of Perceived Ease Of Use: Development and Test. Decision Sciences, 27(3), 451-481. 